\title{
Prevalence of Burnout among Resident Physicians in Mazandaran University of Medical Sciences, Iran
}

\author{
Fatemeh Sheikhmoonesi ${ }^{1}$, Fatemeh Khani ${ }^{2}$, Mohammad Khademloo ${ }^{3} \&$ Seyyedeh Fatemeh Bahari Saravi ${ }^{4}$ \\ ${ }^{1}$ Psychiatrist, MD, Fellowship of Psychotherapy, Associate Professor of Psychiatry, Mazandaran University of \\ Medical Sciences, Psychiatry and Behavioral Sciences Research Center, Addiction Institute, Sari, Iran \\ ${ }^{2}$ General Physician, Sari, Iran \\ ${ }^{3} \mathrm{PhD}$, Social Medicine, Mazandaran University of Medical Sciences, Sari, Iran \\ ${ }^{4}$ Psychiatrist, MD, Askarieh Hospital, Isfahan, Iran \\ Correspondence: Seyyedeh Fatemeh Bahari Saravi, Psychiatrist, MD, Askarieh Hospital, Isfahan, Iran.
}

Received: December 8, 2016 Accepted: February 8, 2017 Online Published: February 28, 2017

doi:10.5539/gjhs.v9n4p50 URL: https://doi.org/10.5539/gjhs.v9n4p50

\begin{abstract}
Introduction: Burnout is a state of mental and physical exhaustion which is developed under high levels of work-related stress. Burnout during residency training has gained significant attention since it leaves negative impacts on job performance and patient care. This study aimed at investigating the rate of burnout among residents in different medical fields.
\end{abstract}

Method: A descriptive cross sectional study was carried out in 170 medical residents in Mazandaran University of Medical Sciences, 2012. Data was collected using a demographic questionnaire and Maslach Burnout Inventory (MBI).

Results: Overall $52 \%$ of residents met burnout criteria ranging from $33 \%$ to $73 \%$ in different fields. There was a significant difference between specialties regarding emotional exhaustion subscale. $(\mathrm{p}=0.022)$. There was also a significant relationship between age and emotional exhaustion, in fact younger residents reported higher emotional exhaustion. $(\mathrm{p}=0.004)$

Conclusions: There was a considerable degree of burnout among residents and we found a relationship between educational field and emotional exhaustion. The highest degree of burnout was observed in Gynecology residents, and highest degree of emotional exhaustion was reported between younger residents.

Keywords: burnout, medical residents, Mazandaran University of Medical Sciences

\section{Introduction}

Job related burnout is an occupational hazard for people-oriented professionals. (Soler et al., 2008)

Burnout is a syndrome of emotional exhaustion, depersonalization and low sense of personal accomplishment that occurs frequently in health care personnel (Melchoir, Bours, Schmitz, \& Wittich, 1997; Zubairi and Noordin, 2016). Symptoms of burnout are exhaustion, frustration, anger, cynicism, a feeling of ineffectiveness and/or fatigue. An important element of this syndrome is a negative impact on job performance (Soler et al., 2008).

Three dimensions of the syndrome are described as: 1. Emotional exhaustion (EE) which is the depletion of one's emotional resources and reflects the basic stress dimension of burnout; 2. Depersonalization (DP) that usually develops due to the effect of EE and exhibits features of detachment and eventually, dehumanization, and 3. Decreased personal accomplishment (PA) that reflects reduced feeling of competence and productivity at work, which are linked to depression (Soler et al., 2008; Melchoir et al., 1997; Zubairi \& Noordin, 2016; Soleymannejad, Hamdami \& Soodi, 2011).

Compared with general population, health workers are reported to experience higher levels of burnout. Among health care trainings, residency programs are usually associated with considerable degree of burnout. Studies show that between $18 \%$ and $76 \%$ of medical residents suffer from burnout syndrome (Rutherford and Oda, 2014). In such conditions the individual's ability to build rapport, sort through medical problems and diagnostic dilemmas, and treatment decision making are diminished (Zubairi \& Noordin, 2016; Ishak et al., 2009).

Some studies on the reasons causing burnout in residency training reported that time demands, lack of control over time management, volume and scheduling of working hours, difficult job situations and interpersonal relations as 
stressors leading to burnout (Ishak et al., 2009).

Distressing situations due to burnout may contribute to physical illness and psychiatric morbidity, including cardiovascular diseases and high rates of drug abuse (Zubairi and Noordin, 2016; Olson, Odo, Duran, Pereira, \& Mandel, 2014). Consequently, institutions face increased employee turnover, absenteeism, poor job performance and higher likelihood of medical errors (Zubairi \& Noordin, 2016).

Burnout develops cumulatively over an extended time line period and the rate of burnout among medical students ranges from $28 \%$ to $45 \%$ (Ishak et al., 2009).

Burnout has been the subject of interest over the last 2 to 3 decades (Rutherford and Oda, 2014; Muzafar et al., 2015), but paucity of information exists on this phenomenon in Iran. Medical residents encounter high levels of educational stress, work load and financial restricts. Meanwhile, they are responsible for patients care and have a key role in medical decisions in teaching hospitals. Therefore, in this research, we aimed at studying the rate of burnout among residents in different medical fields and to identify predisposing factors of this syndrome and to propose suggestions for decreasing burnout during residency training in Iran.

\section{Materials and Method}

Participants were 170 medical residents in three different levels and different medical fields. The study was conducted in Mazandaran teaching hospitals in Sari, Iran in 2012.

Maslach Burnout Inventory (MBI) and demographic questionnaire (Maslach and Jackson, 1981) were handed out personally to residents by a medical student. The study obtained approval from Mazandaran University of Medical sciences ethic committee and then all participants were assured that their responses were anonymous and confidential. The demographic questionnaire included: age, gender, marital status, number of children, level and department of training, being local or not, and history of medical diseases.

Burn out was measured using MBI which is the most commonly used questionnaire to measure burnout in research studies. It is a self-administered, 22 item questionnaire that was developed to measure burnout in human services workers and is a gold standard in measuring burnout. The full MBI includes 22 questions. 9 evaluating emotional exhaustion, 5 quantitating depersonalization, and 8 assessing personal accomplishments of burnout syndrome. This study assessed emotional exhaustion through questions such as" I feel like I am at the end of my rope" and " I feel burned out from my work", personal accomplishment with questions such as " I have accomplished many worthwhile things in this job", and depersonalization with questions such as" I feel I treat some of my colleagues and patients as if they were impersonal objects".

The MBI items are rated from 0 to $6(0=$ never, $1=\mathrm{a}$ few times per year, $2=$ once a month, $3=\mathrm{a}$ few times per month, $4=$ once a week, $5=$ a few times per week, and $6=$ every day).

Burnout is detected using cut off scores of high emotional exhaustion ( $\geq 27)$, high depersonalization $(\geq 10)$, and low personal accomplishment $(\leq 33)$. (Ishak et al., 2009)

This questionnaire has been extensively validated across different countries (Zubairi \& Noordin, 2016; Ishak et al., 2009; Nyssen, Hansez, Baele, \& Lamy, De keyser, 2003; Embriaco et al., 2007).

The validity and reliability of the Persian translation of MBI has been proved by Filian in 1992 and also Yousefi in 2006. (Filian, 1992; Jalali, Sadeghipour roodsari, \& Bassirnia, 2013; Yousefi \& Ghasemi, 2006; Soroush, Zargham boroujeni, \& Namnabati, 2016).

Reliability for MBI scale using Cronbach alpha was 0.86 and for the three subscales was 0.88 for emotional exhaustion, 0.76 for depersonalization and 0.79 for personal accomplishment (Yousefi \& Ghasemi, 2006; Soroush et al., 2016; Ashtari, Farhady, \& Khodaee, 2009).

Data was then analyzed in SPSS ver. 19 and Chi-square test, Pearson correlation coefficient test, and T-test were used to analyze the data.

\section{Results}

Out of 170 residents training in Mazandaran University of Medical Sciences, 106 residents (60\%) agreed to participate in the study. Participants were training in three levels in different departments including: cardiology, pediatrics, general surgery, obstetrics and gynecology, radiology, pathology, internal medicine, emergency medicine, infectious medicine, psychiatry, and anesthesiology.

Table 1 shows the distribution of burnout and the three dimensions among residents. With the high emotional exhaustion, high depersonalization and low personal accomplishment being $4.7 \%, 16 \%$ and 47.25 respectively.

As shown in table 2, 55 out of 106 residents reported burnout symptoms ranging from 33\% to $73 \%$ in different fields of residency. Burn out rates were as follows: 73\% in Obstetrics and Gynecology, 60\% in General surgery, 57\% in Pediatrics, 55\% in Cardiology, 50\% in Infectious medicine, 44\% in Internal medicine, 42\% in Psychiatry, 40\% 
in Emergency medicine, 37\% in Radiology, and 37\% in Pathology.

Emotional exhaustion was reported to be high among Obstetrics and Gynecology residents (20\%) followed by infectious medicine residents (16.7\%) and General surgery residents (10\%). There was a significant difference in emotional exhaustion subscale among different specialties of residency. $(\mathrm{p}=0.022)$

Table 1. Prevalence of three dimensions of burnout among residents

\begin{tabular}{|c|c|c|c|c|c|c|c|c|c|c|}
\hline & \multicolumn{3}{|c|}{ Personal accomplishment } & \multicolumn{3}{|c|}{ Depersonalization } & \multicolumn{3}{|c|}{ Emotional exhaustion } & \multirow{2}{*}{ Total } \\
\hline & High & Moderate & Low & High & Moderate & Low & High & Moderate & Low & \\
\hline $\mathbf{N}(\%)$ & $30(28.3)$ & $26(24.5)$ & $50(47.2)$ & $17(16.0)$ & $11(10.4)$ & $78(73.6)$ & $5(4.7)$ & $23(21.7)$ & $78(73.6)$ & $106(100)$ \\
\hline
\end{tabular}

Table 2. Distribution of burnout according to specialties

\begin{tabular}{lllll}
\hline $\begin{array}{l}\text { Specialties, } \\
\mathbf{n}(\%)\end{array}$ & $\begin{array}{l}\text { High emotional } \\
\text { exhaustion, } \\
\mathbf{n}(\%)\end{array}$ & $\begin{array}{l}\text { High } \\
\text { depersonalization, } \\
\mathbf{n}(\%)\end{array}$ & $\begin{array}{l}\text { Low personal } \\
\text { accomplishment, } \\
\mathbf{n}(\%)\end{array}$ & $\begin{array}{l}\text { Burnout } \\
\text { syndrome, } \\
\text { n(\%) }\end{array}$ \\
\hline Cardiology, 18(16) & 0 & $3(16.7)$ & $9(50)$ & $10(55)$ \\
General surgery, 10(9) & $1(10)$ & $4(40)$ & $5(50)$ & $6(60)$ \\
Internal medicine, 9(8) & 0 & 0 & $4(44)$ & $4(44)$ \\
Psychiatry, 14(13) & 0 & $1(7.1)$ & $6(42.9)$ & $6(42)$ \\
Emergency medicine, 5(4) & 0 & $2(40)$ & 0 & $2(40)$ \\
Pathology, 9(8) & 0 & $1(11.1)$ & $3(33.3)$ & $3(33)$ \\
Radiology, 8(7) & 0 & $1(12.5)$ & $3(37.5)$ & $3(37)$ \\
Anesthesiology, 5(4) & 0 & 0 & $3(60)$ & $3(60)$ \\
Pediatrics, 7(6) & 0 & 0 & $4(57)$ & $4(57)$ \\
Infectious disease, 6(5) & $1(16.7)$ & $1(16.7)$ & $3(50)$ & $3(50)$ \\
Obstetrics and gynecology, 15(14) & $3(20)$ & $4(26.7)$ & $10(66.7)$ & $11(73)$ \\
\hline
\end{tabular}

$\%$ the percentage is relative frequency of each specialty to total number of specialties.

Table 3 shows the demographic factors and its association with burnout syndrome.

In this study participants were divided into three groups regarding their age, according to other studies age is one of the most important factors in burnout syndrome (Rutherford and Oda, 2014; Turgut et al., 2016; Muzafar et al., 2015).

The results showed that younger residents (aged 26-30) reported higher levels of burnout in all three subscales. And there was a statistically significant association between residents' age and emotional exhaustion subscale $(\mathrm{p}=0.004)$ but not with other two subscales.

Table 3. Demographic features of the participants

\begin{tabular}{|c|c|c|c|c|}
\hline Variables & Frequency (\%) & $\begin{array}{l}\text { High emotional } \\
\text { exhaustion }\end{array}$ & $\begin{array}{l}\text { High } \\
\text { depersonalization }\end{array}$ & $\begin{array}{l}\text { Low personal } \\
\text { accomplishment }\end{array}$ \\
\hline \multicolumn{5}{|l|}{ Gender } \\
\hline Male & $54(50.9)$ & $2(3.7)$ & $9(16.7)$ & $21(38.9)$ \\
\hline Female & $52(49.1)$ & $3(5.8)$ & $8(15.4)$ & $29(55.8)$ \\
\hline p-value & & 0.602 & 0.641 & 0.217 \\
\hline \multicolumn{5}{|l|}{ Age } \\
\hline $26-30 y$ & $32(30.2)$ & $4(12.5)$ & $9(28.1)$ & $19(59.4)$ \\
\hline $31-35 y$ & $51(48.1)$ & 0 & $5(9.8)$ & $21(41.2)$ \\
\hline Over 36y & $23(21.7)$ & $1(4.3)$ & $3(13)$ & $10(43.5)$ \\
\hline p-value & & $0.004 * *$ & 0.116 & 0.338 \\
\hline \multicolumn{5}{|c|}{ Marital status } \\
\hline Married & $73(68.9)$ & $4(5.5)$ & $9(12.3)$ & $32(43.8)$ \\
\hline
\end{tabular}




\begin{tabular}{|c|c|c|c|c|}
\hline Single & $33(31.1)$ & $1(30)$ & $8(24.2)$ & $18(54.5)$ \\
\hline p-value & & 0.327 & 0.301 & 0.495 \\
\hline \multicolumn{5}{|c|}{ Number of children } \\
\hline No child & 63(59.4) & $4(6.3)$ & $14(22.2)$ & $32(50.8)$ \\
\hline One child & $24(22.6)$ & 0 & $2(8.3)$ & $10(41.7)$ \\
\hline 2 or more & $19(18)$ & $1(5.6)$ & 1(5.6) & $6(33.3)$ \\
\hline p-value & & 0.399 & 0.466 & 0.493 \\
\hline \multicolumn{5}{|c|}{ Chronic illness } \\
\hline Yes & $6(5.7)$ & 0 & 0 & $3(50)$ \\
\hline No & $100(94.3)$ & $5(5)$ & $17(17)$ & $25(25)$ \\
\hline p-value & & 0.796 & 0.511 & 0.478 \\
\hline \multicolumn{5}{|l|}{ Being local } \\
\hline Yes & $62(58.5)$ & $3(4.8)$ & $10(16.1)$ & $27(43.5)$ \\
\hline No & $44(41.5)$ & $2(4.5)$ & $7(15.9)$ & $23(52.3)$ \\
\hline p-value & & 0.961 & 0.243 & 0.319 \\
\hline \multicolumn{5}{|c|}{ Level of residency } \\
\hline First year & $31(29.2)$ & $3(9.7)$ & $8(25.8)$ & $16(51.6)$ \\
\hline Second year & $38(35.8)$ & 0 & $4(10.5)$ & $12(31.6)$ \\
\hline Third year & $37(34.9)$ & $2(5.4)$ & $5(13.5)$ & $22(59.5)$ \\
\hline p-value & & 0.318 & 0.453 & 0.089 \\
\hline
\end{tabular}

*Fisher exact test is used.

There was no significant difference in the pattern of burnout regarding gender, marital status, number of children, level of residency, being local, and past medical history. ( $\mathrm{p} \geq 0.05)$

\section{Discussion}

Statistical analysis in this study showed that up to $52 \%$ of residents in Mazandaran University of Medical Sciences suffered from high levels of burnout (33\% to $73 \%$ ) in different medical fields. This matches well with several studies on burnout syndrome among residents.

For instance, Martini et al found the burnout rate among residents to be $49 \%$, ranging from $27 \%$ to $75 \%$ in different fields (Ishak et al., 2009), (Martini, Arfken, Churchill \& Balon, 2004)

In contrast, Shanafelt et al reported 76\% burnout in Internal medicine residents (Shanafelt, Bradley, Wipf, \& Back, 2002), which was significantly different from present results (44\%)

Nyssen et al studied Anesthesiology residents in 2003 of whom 34\% reported burnout but none of them reported high levels of emotional exhaustion and depersonalization. (Nyssen et al., 2003)

Similarly Castelo et al studied Obstetrics and Gynecology residents and found a $58 \%$ rate of burnout among them (Ishak et al., 2009; Castelo-Branco et al., 2007; Baria, Spanu, Baban, \& Todea, 2014), which was lower compared with $73 \%$ burnout rate in our study.

Emotional exhaustion and depersonalization rate in Obstetrics and Gynecology residents in the investigation of Becker et al was found to be $50 \%$ and $32 \%$, respectively which was much higher than our results (Becker, Milad \& Klock, 2006).

A study by Fahrenkopf showed $75 \%$ of Pediatric residents to have higher levels of EE and depersonalization (Fahrenkopf et al., 2008) but in our study no reports of high EE or depersonalization in Pediatric residents were found.

Similar to previous studies, we observed a quite high rate of burnout among physicians. Several causes are found to be responsible for burnout including: quantitative work overload situations, lack of job resources, low levels of social support or autonomy and emotionally challenging situations such as uncooperative, aggressive or mistrustful patients, those who hold unrealistic expectations and patients with end stage diseases..

One of the main reasons leading to difference between results of burnout studies is the different educational programs in different countries, and also the difference between patient population and number of residents in teaching hospitals. (Alosaimi, Alghamdi, Aladwani, \& Kazim, Almufleh, 2016) 
According to current study younger residents (26-30 years old) showed higher levels of burnout in all three subscales $(\mathrm{p}=0.004)$ which matches with the results of other studies.

In a study on burnout among family doctors, high levels of burnout was strongly associated with younger age (Soler et al., 2008). Similarly Woodside et al demonstrated a higher level of depersonalization in younger residents of family medicine and psychiatry (Woodside, Miller, Floyd, Mc Gowen, \& Pfotmiller, 2008).on the other hand some studies found no significant relationship between residents age and burnout. (Turgut et al., 2016) and interestingly Muzafar et al in 2015 reported higher levels of burnout in senior medical students in compare to younger ones.(Muzafar et al., 2015)

To explain these facts, one could say that with increasing work experience and getting used to act in stressful situations, increasing educational and skills level, the burnout rate decreases. In the first year of work and in younger residents, there will be more burnout reports due to new job and responsibilities and when the years go by, residents feel much more confident about their abilities.

In this study we found that level of emotional exhaustion and depersonalization was higher among first year residents compared with other levels of residency but the difference was not statistically significant.

Martini et al suggested that being a fist year resident was associated with higher burnout rate $77.3 \%$ in first year residents vs $41.8 \%$ in second and higher level residents) (Martini et al., 2004)

A study by Rosen et al showed $4.3 \%$ burnout at the beginning of intern year of Internal medicine residents. In that study a significant increase was observed in both depersonalization and emotional exhaustion subscales by the end of the first year (55.3\%). (Rosen, Gimotty, Shea, \& Bellini, 2006). Similar to those studies a study by Turgut et al showed that emotional exhaustion and depersonalization were significantly higher among second year residents in compare to third and fourth year residents (Turgut et al., 2016).

This results can be due to higher workload, night shifts, new workplace experience, and being responsible for people's life.

In present study we found no difference between male and female participants on emotional exhaustion and depersonalization subscales. Although female participants reported a higher level of reduced personal accomplishment but this was not statistically significant compared with male residents.

There are different results in this area in various studies. For instance, Ishak WW et al demonstrated significantly lower burnout level in EE and depersonalization subscale in female residents. (Ishak et al., 2009)

Also, in the study of burnout in family medicine and psychiatry residents, female residents had lower scores on depersonalization scale (Woodside et al., 2008).

However, in different results Atef et al found that burnout scales in female physicians were significantly higher than male physicians in Isfahan, Iran (Atef, Rooholamin, Noori, \& Molavi, 2006). Same results were found in a study by Muzafar et al on medical students suggesting that female students had higher burnout levels (Muzafar et al., 2016).

Female physicians might experience higher burnout levels regarding emotional liability, being more committed to job, and being more responsible than men. Also, female physicians' role as homemakers, managing all the household problems and nurturing the children adds to the amount of stress that they experience.

There was no significant association between marital status of residents and burnout levels in this study which was consistent with the results of Shanafelt et al (2002), (Martini, Arfken, \& Balon, 2006) and also Park et al. (2016).

In 2004 Martini et al found that being single was significantly associated with burnout (65.2\% burnout in divorced or single residents and $40 \%$ burnout in married residents)

We can conclude that being married and having a spouse with a supporting and comforting role can reduce anxiety and stress and eventually reduce the burnout rate.

There was no significant relationship between number of children's of residents and burnout in this study. Which is consistent with the results of Park et al and Olson et al studies (Park at al, 2016; Olson et al., 2014). Also Martini et al (2004) reported that $56.4 \%$ of residents without children met the criteria for burnout while it was found in $36.4 \%$ of residents with one or more child, (indicating no significant difference).

In a review article performed by Martini et al. (2004), Collier et al showed that having children during residency resulted in lower rate of depression and cynicism as well as increase in humanistic feelings.

Being a parent could be a protective factor against burnout. It might be assumed that parental responsibility for looking after children would add to burnout but in fact it can result in less detachment and depersonalization. (Ishak et al., 2009), however other studies showed that parenting had no effect on burnout (Ishak et al., 2009).

The study had a few limitations, which should be considered in future studies. There are dimensions in burnout risk 
factors that has not been addressed by Maslach inventory such as interactions of residents in different levels with each other, interactions of residents with the attending. The cross sectional design of the study limits determining the causality of the subject. And according to different residency training programs in different countries it is possible that the workload and psychological burden also varies. There may be the possibility that the students with more burnout were less likely to join the study.

\section{Conclusion and Future suggestions}

As shown in our study, burnout is quite prevalent among residents in Mazandaran University of Medical Sciences and ignoring this, can have negative impact on both physicians and patients, such as depression, medical illness and suicidal tendencies in residents and also increasing the risk of medical errors and patient's safety. Burnout is affected by both social and personal origins. To prevent burnout, both of these domains should be addressed. Some interventions that could reduce burnout in workplace include: reducing work hours, lower work load, developing stress-management programs, more breaks, and different roles in workplace (research, teach and supervise).

There was a significant association between emotional exhaustion and the subspecialty of medical fields with OB \& GYN residents reporting higher rate of burnout. We suggest that reducing workload and increasing the number of residents in some specialties like OB \& GYN and General surgery might improve the quality of work of residents and decrease unwanted medical errors.

In this study we investigated only the prevalence of burnout among residents, therefor; further studies should address the risk factors of burnout in residency, so with optimal changes in residency training programs the burnout rate reduces too.

\section{Competing Interests Statement}

The authors declare that there is no conflict of interests regarding the publication of this paper.

\section{References}

Alosaimi, F., Alghamdi, A., Aladwani, B., Kazim, S., \& Almufleh, A. (2016). Work-related stress and stress-coping strategies in residents and administrative employees working in a tertiary care hospital in KSA. $\begin{array}{lllll}\text { Journal of Taibah University of Medical Sciences, } 11(1), & 32-40 .\end{array}$ https://doi.org/10.1016/j.jtumed.2015.08.009

Ashtari, Z., Farhady, Y., \& Khodaee, M. R.(2009). Relationship between job burnout and work performance in a sample of Iranian mental health staff. African journal of psychiatry, 2, 71-74.

Atef, L., Rooholamin, M., Noori, A., \& Molavi, H. (2006). Prevalence of burnout among general surgeons and internists in Isfahan. Knowledge and Research in applied psychology, 29,129-151. (In Persian)

Baria, M., Spanu, F., Baban, A., \& Todea, C. (2014). Burnout and occupational factors among Romanian healthcare professionals working in obstetrics and gynecology clinics. Procedia-social and behavioral sciences, 127, 36-40. https://doi.org/10.1016/j.sbspro.2014.03.208

Becker, J. L., Milad, M. P., Klock, S. C. (2006). Burnout, depression, and career satisfaction: cross-sectional study of obstetrics and gynecology residents. American journal of obstetrics and gynecology, 195(5), 1444-1449. https://doi.org/10.1016/j.ajog.2006.06.075

Castelo-Branco, C., Figueras, F., Eixarch, E., Quereda, F., Cancelo, M. J., Gonzalez, S., \& Balasch, J. (2007). Stress symptoms and burnout in obstetrics and gynecology residents. International journal of obstetrics and gynecology, 114, 94-98.

Embriaco, N., Azoulay, E., Barrau, K., Kentish, N., Pochard, F., Loundou, A., \& Papazian, L. (2007). High level of burnout in intensivists. American journal of respiratory and critical care medicine, 175, 686-692. https://doi.org/10.1164/rccm.200608-1184OC

Fahrenkopf, A. M., Sectish, T. C., Barger, L. K., Sharek, P. J., Lewin, D., Chiang, V. W., ... Landrigan, C. P. (2008). Rates of medication errors among depressed and burned out residents: Prospective cohort study. Bmj, 336(7642), 488-491. https://doi.org/10.1136/bmj.39469.763218.BE

Filian, A. (1992). Burnout syndrome and its association with coping mechanisms in Iranian nurses. Doctoral Dissertation, Tarbiat modares University, Tehran Iran, (Persian).

Ishak, W. W., Lederer, S., Mandili, C., Nikravesh, R., Seligman, L., Vasa, M., ... Bernstein, C. A.(2009). Burnout during residency training: A literature review. Journal of graduate medical education, 1(2), 236-242. https://doi.org/10.4300/JGME-D-09-00054.1

Jalili, M., Sadeghipour, Gh., \& Bassirnia, A. (2013). Burnout and associated factors among Iranian emergency medicine practitioners. Iranian journal of public health, 42(9), 1034-1042.

Martini, S., Arfken, C. L., \& Balon, R. (2006). Comparison of burnout among medical residents before and after 
the implementation of work hour limits. Academic Psychiatry, 30(4), 352-355. https://doi.org/10.1176/appi.ap.30.4.352

Martini, S., Arfken, C. L., Churchill, A., \& Balon, R.(2004). Burnout comparison among residents in different medical specialties. Academic Psychiatry, 28(3), 240-242. https://doi.org/10.1176/appi.ap.28.3.240

Maslach, Ch., \& Jackson, S. (1981). The measurement of experienced burnout. Journal of occupational behavior, 2, 99-113. https://doi.org/10.1002/job.4030020205

Melchoir, M. E., Bours, G. J., Schmitz, P., Wittich, Y. (1997). Bournout in Psychiatric nursing: a meta- analysis of related variables. Journal of Psychiatric mental health nursing, 4(3), 193-201. https://doi.org/10.1046/j.1365-2850.1997.00057.x

Muzafar, Y., Khan, .H., Ashraf, .H., Hussain, W., Sajid, H.,Tahir, M., ... Ahmad, W. (2015). Burnout and its associated factors in medical students of Lahore, Pakistan. Cureus, 7(11), e390. https://doi.org/10.7759/cureus.390

Nyssen, A. S., Hansez, I., Baele, P., Lamy, .M., \& De Kyser, V.(2003). Occupational stress and burnout in anesthesia. British journal of anesthesia, 90(3), 333-337. https://doi.org/10.1093/bja/aeg058

Olson, Sh., Odo, N., Duran, A., Pereira, A., \& Mandel, J. (2014). Burnout and physical activity in Minnesota internal medicine resident physicians. Journal of graduate medical education, 12, 669-674. https://doi.org/10.4300/JGME-D-13-00396

Park .Ch., Lee, Y., Hong. M., Jung, Ch., Synn, Y., Kwack. Y., ... Bahn, G. A. (2016). multicenter study investigating empathy and burnout characteristics in medical residents with various specialties. Journal of Korean medical science, 31, 590-597. https://doi.org/10.3346/jkms.2016.31.4.590

Rosen, M., Gimotty, P. A., Shea, J. A., \& Bellini, L. M. (2006). Evolution of sleep quantity, sleep deprivation, mood disturbances, empathy, and burnout among interns. Academic medicine, 81(1), 82-85. https://doi.org/10.1097/00001888-200601000-00020

Rutherford, K., \& Oda. J.(2014). Family medicine residency training and burnout: a qualitative study. Canadian medical education journal, 5(1), 13-23.

Shanafelt, T. D., Bradley, K. A., Wipf, J. E., Back, A. L. (2002). Burnout and self-reported patient care in an internal medicine residency program. Annals of internal medicine, 136(5), 358-367. https://doi.org/10.7326/0003-4819-136-5-200203050-00008

Soler, J. K.,Yaman, H., Esteva, M., Dobbs, F., Asenova, R. S., Katic, M., ... Lionisc, C.(2008). Burnout in European family doctors: The EGPRN study. Family practice, 25(4), 245-265. https://doi.org/10.1093/fampra/cmn038

Soleymannejad, A., Hamdami, P., Soodi, H. (2011). Investigating the relationship between coping strategies and burnout with mental health among physicians in Urmia. Journal of Urmia nursing and midwifery faculty, 10(2), 226-236 (Persian).

Soroush, F., Zarghami Boroujeni, A., \& Namnabati, M. (2016). The relationship between nurses clinical competence and burnout in neonatal intensive care units. Iranian journal of nursing and midwifery research, 21(4), 424-429. https://doi.org/10.4103/1735-9066.185596

Turgut, N., Karacalar, S., Polat, C., Kiran, O., Gultop .F., Kalyon, S., ... Kaya .E. (2016). Burnout syndrome during residency. Turk Journal anaesthesiol reanim, 44, 258-264.

Woodside, J. R., Miller, .M. N., Floyd, M. R., Mc Gowen, K. R., \& Pfotmiller, D. T. (2008). Observations on burnout in family medicine and psychiatry residents. Academic psychiatry, 32(1), 13-19. https://doi.org/10.1176/appi.ap.32.1.13

Yousefy, A. R., \& Ghassemi. Gh. R. (2006). Job burnout in psychiatric and medical nurses in Isfahan, Islamic Republic of Iran. Eastern Mediterranean health journal, 12(5), 662-669.

Zubairi, A. J., \& Noordin, S. (2016). Factors associated with burnout among residents in a developing country. Annals of medicine and surgery, 6, 60-63. https://doi.org/10.1016/j.amsu.2016.01.090

\section{Copyrights}

Copyright for this article is retained by the author(s), with first publication rights granted to the journal.

This is an open-access article distributed under the terms and conditions of the Creative Commons Attribution license (http://creativecommons.org/licenses/by/4.0/). 